\title{
Examining Religious Commitment, Perfectionism, Scrupulosity, and Well-Being Among LDS Individuals
}

Kawika Allen

Brigham Young University, gekawika_allen@byu.edu

Kenneth T. Wang

University of Missouri

Follow this and additional works at: https://scholarsarchive.byu.edu/facpub

Part of the Regional Sociology Commons

\section{Original Publication Citation}

Allen, G. E. K., \& Wang, K. T. (2014, March 17). Examining Religious Commitment, Perfectionism, Scrupulosity, and Well-Being Among LDS Individuals. Psychology of Religion and Spirituality. Advance online publication. http://dx.doi.org/10.1037/a0035197

\section{BYU ScholarsArchive Citation}

Allen, Kawika and Wang, Kenneth T., "Examining Religious Commitment, Perfectionism, Scrupulosity, and Well-Being Among LDS Individuals" (2014). Faculty Publications. 3170.

https://scholarsarchive.byu.edu/facpub/3170

This Peer-Reviewed Article is brought to you for free and open access by BYU ScholarsArchive. It has been accepted for inclusion in Faculty Publications by an authorized administrator of BYU ScholarsArchive. For more information, please contact ellen_amatangelo@byu.edu. 


\section{Psychology of Religion and Spirituality}

\section{Examining Religious Commitment, Perfectionism, Scrupulosity, and Well-Being Among LDS Individuals}

G. E. Kawika Allen and Kenneth T. Wang

Online First Publication, March 17, 2014. http://dx.doi.org/10.1037/a0035197

CITATION

Allen, G. E. K., \& Wang, K. T. (2014, March 17). Examining Religious Commitment, Perfectionism, Scrupulosity, and Well-Being Among LDS Individuals. Psychology of Religion and Spirituality. Advance online publication. http://dx.doi.org/10.1037/a0035197 


\title{
Examining Religious Commitment, Perfectionism, Scrupulosity, and Well-Being Among LDS Individuals
}

\author{
G. E. Kawika Allen \\ Brigham Young University
}

\author{
Kenneth T. Wang \\ University of Missouri
}

\begin{abstract}
This study examined the relationships and interactions between religious commitment, perfectionism, scrupulosity, and psychological well-being among Latter-Day Saints (LDS or Mormons). The results showed a positive association between religious commitment and satisfaction with life. Scrupulosity partially mediated the relationship between maladaptive perfectionism and depression, anxiety, and satisfaction with life. The sample majority was classified as adaptive perfectionists, reporting higher intra- and interpersonal religious commitment, self-esteem, and satisfaction with life, and lower levels of anxiety and depression than the maladaptive and nonperfectionists. Additional results are provided. Implications of these findings are outlined.
\end{abstract}

Keywords: religiosity, perfectionism, scrupulosity, well-being, Latter-Day Saints

As the United States continues to grow in culturally diverse ways, additional attention to and research on different communities is needed (Allen \& Heppner, 2011). One of the ways that the American society has collectively evolved has been through religion. The emersion of various religions and the constitutional freedoms given to Americans to choose how they desire to worship, pray, and study religious text has made living in and becoming a citizen of the United States very appealing for those wanting to escape religious persecution and find religious freedom. This freedom for religiosity and movement has been one of the most fundamental values of American society.

Religion and the psychology of religion have been gaining scholarly attention in psychological literature (Allen \& Heppner, 2011; Bergin, 1991; Cervantes \& Parham, 2005; Richards \& Bergin, 1997; Worthington et al., 2003). Allport and Ross's (1967) early work of a two-dimension model of religiosity, intrinsic and extrinsic motivation, could arguably be considered as the birth of the secular investigation into religion related to motivation. Research has also pointed to the difference between religiosity and spirituality (Cervantes \& Parham, 2005; Walsh, 1999). According to Walsh (1999), religiosity differs from spirituality in that a person who affiliates with a specific religion is characterized by an organized belief system and specific moral values and behaviors that are mutually shared among other persons belonging to the same institutionalized religion. These individuals often center their

G. E. Kawika Allen, Department of Counseling Psychology and Special Education, Brigham Young University, and Kenneth T. Wang, Department of Educational, School, and Counseling Psychology, University of Missouri.

Correspondence concerning this article should be addressed to G. E. Kawika Allen, Department of Counseling Psychology and Special Education, Brigham Young University, 340 MCKB, Provo, UT 84602. E-mail: gekawika_allen@byu.edu beliefs on a God or the idea of a Higher Power, which includes their involvement and devotion to a specific religious and faithdriven group. In contrast, spirituality involves traits of a person with transcendent beliefs that are overarching and views life as a journey to greater awareness and wholeness (Cervantes \& Parham, 2005; Parham, 2002; Walsh, 1999).

Scholars of religion and religious living have observed many favorable associations between higher levels of religious involvement and overall psychological well-being (i.e., decreased depressive and anxiety symptoms as well as increased self-esteem; Jackson \& Bergman, 2011; Allen \& Heppner, 2011). Clinicians in the field of psychology have also noticed a rise of religious fervor in the United States. Richards and Bergin (1997) maintained that there is a spiritual energy in the United States and "it has created a powerful cultural demand for psychotherapists to be more aware of and sensitive to religious and spiritual issues" (p. 6). They also postulated that unfortunately relatively few mental health clinicians are appropriately trained or prepared to work effectively with such issues (Bergin, 1991; Richards \& Bergin, 1997). To work with highly religious individuals and understand this religious way of living, a spiritual strategy should be addressed that can enhance the competence of these clinicians to better assist their clients. Although there have been numerous studies on religiosity and psychological well-being among diverse populations (Allen \& Heppner, 2011; Jackson \& Bergman, 2011; Abdel-Khalek, 2011; Yeh, Arora, \& Wu, 2006; Yeh, Inman, Kim, \& Okubo, 2006; Cervantes \& Parham, 2005; Richards \& Bergin, 1997), little is known about members of The Church of Jesus Christ of LatterDay Saints (LDS; the organization with which Mormons are affiliated), their well-being (i.e., self-esteem and life satisfaction), and psychological adjustments, primarily depression and anxiety.

Since its organization on April 6, 1830 in Fayette, NY, the LDS Church and its people had to move to various places because of persecution by others in the surrounding areas between the years of 1830 to 1847 . They finally reached their destination by foot (pulling wagons) into the Salt Lake Valley in the summer of 1847 
(Barrett, 1973). Many LDS lives were lost because of persecution, violence, and from winter exposure during the movement westward. Since then, the LDS Church has grown to over 14 million members worldwide.

One of the main doctrines of the LDS Church is "come unto Christ, and be perfected in him" (Mormon scripture; Moroni 10:32), which doctrine encourages members of this faith to live a high moral and values-based standard of living.

The existence of perfectionism in diverse groups has been well documented over the years (Slaney, Mobley, Trippi, Ashby, \& Johnson, 1996; Shafran \& Mansell, 2001; Stoeber \& Otto, 2006; Grzegorek, Slaney, Franze, \& Rice, 2004; Rice \& Slaney, 2002; Wang, 2010). There has been convincing evidence of the impact of perfectionism (both adaptive and maladaptive) on mental health (Shafran \& Mansell, 2001; Stoeber \& Otto, 2006). In particular, maladaptive perfectionism (i.e., also described as discrepancy: a tendency to feel that one is never good enough) has been associated with depressive and anxiety symptoms (e.g., Grzegorek et al., 2004; Rice \& Slaney, 2002; Wang, 2010), whereas adaptive perfectionists are more likely to feel self-acceptance and less depressive and anxious symptoms when experiencing their perceived failure of reaching their high standards. Moreover, individuals have been classified into different types of perfectionists based on their combination of their levels of adaptive (i.e., high standards) and maladaptive (i.e., discrepancy) perfectionism (e.g., Rice \& Slaney, 2002). Specifically, maladaptive perfectionists are those with both high standards and discrepancy, whereas adaptive perfectionists are those with high standards but low discrepancy. Maladaptive perfectionists have been found to report higher levels of depressive and anxious mood compared to adaptive perfectionists and nonperfectionists (e.g., Rice \& Slaney, 2002).

There are very few studies that have examined the association between perfectionism and religious factors. One study examined religious dysfunctional perfectionism, in which perfectionistic tendencies were manifested in religious-specific behaviors and beliefs (Craddock, Church, Harrison, \& Sands, 2010). In this study with a sample of college students from various religious backgrounds, general maladaptive perfectionism and family rigidity were found to be significant predictors of religious dysfunctional perfectionism. In another study (Crosby, Bates, \& Twohig, 2011), the factor defined as high standards was found to be significantly and positively correlated with adaptive religiosity (intrinsic orientation), whereas discrepancy was positively associated with maladaptive religiosity (extrinsic orientation). Moreover, psychological inflexibility mediated the relationship between maladaptive religiosity and maladaptive perfectionism. In addition, religiously oriented group counseling was found to be an effective intervention for treating self-defeating perfectionism through a qualitative study with 15 LDS students (Richards, Owen, \& Stein, 1993). Clearly, there should be more studies examining the role of perfectionism among religious populations.

Another possible variable related to perfectionism and religiosity is the concept of scrupulosity, which is defined as pervasive concerns around sinful activity and somewhat uncontrollable behaviors to participate in religious acts repetitively (Abramowitz, Huppert, Cohen, Tolin, \& Cahill, 2002). Recent studies on scrupulosity (Foa et al., 1995; Summerfeldt, Antony, Downie, Richter, \& Swinson, 1998; Nelson, Abramowitz, Whiteside, \& Deacon, 2006) have found a persistent pattern of fears around sin and urges to perform excessive religious behaviors, which researchers have recognized as symptoms of obsessive-compulsive disorder. Scrupulosity has also been related to several cognitive aspects of obsessive-compulsive disorder, including beliefs about the importance of, and need to control intrusive thoughts, an inflated sense of responsibility, and moral thought-action fusion (Nelson et al., 2006). Research on the effects of scrupulosity has also been conducted, specifically related to fears of sin and punishment from God on highly religious individuals (Abramowitz et al., 2002), which have also led to higher levels of anxiety.

Although perfectionism and scrupulosity are fundamentally defined as different psychological constructs, there could be an intersecting component between perfectionistic discrepancy and compulsive concerns about sinful behaviors. In other words, a personality trait of never feeling that one is good enough (perfectionistic discrepancy) could lead to an excessive focus on one's sins (scrupulosity). Thus, scrupulosity may likely be a mediator between discrepancy and psychological well-being in many populations. Further research is needed to examine perfectionism and scrupulosity related to psychological outcomes on highly religious individuals. The literature lacks information related to these aspects of LDS members' well-being. Investigating the impact of religious commitment, perfectionism, and scrupulosity on psychological well-being among religious LDS individuals could serve the dual purpose of helping psychologists assist LDS clients and deepening our understanding of this issue that has national relevance.

This study examined the relationships between religious commitment, perfectionism, and scrupulosity and their impact on psychological outcomes related to depression, anxiety, self-esteem, and satisfaction with life in a strictly LDS context. The study aimed to examine (a) whether elevated levels of religious commitment are associated with lower levels of depression and anxiety as well as higher levels of self-esteem and satisfaction with life; (b) the association between religious commitment and adaptive/maladaptive perfectionism; (c) whether those with higher maladaptive perfectionism are at a greater risk for the detrimental impact of scrupulosity on anxiety, depression, and satisfaction with life; and (d) if scrupulosity mediates the relationships of perfectionistic discrepancy with anxiety, depression, and satisfaction with life.

\section{Method}

The sample of this study includes 267 LDS individuals living in a highly concentrated and faith-based LDS community in a southwest region of the United States. The majority of the participants were White (97\%) and 60\% were women. Participants' ages ranged from 18-68 years with a mean of 23.6. Participants were recruited through fliers and announcements about the study within the community and at a local liberal arts university. Those individuals who were attending the liberal arts university were given a 1-hr school credit for their participation in the study. Respondents were able to participate in the study online.

\section{Instruments}

Religious Commitment Inventory-10 (Worthington et al., 2003) was used to assess religious commitment. It consists of 10 items and two factors: Intrapersonal (cognitive focus) and Interpersonal 
(behavior focus) Religious Commitment. The following are examples of Intrapersonal and Interpersonal Religious Commitment items: "It is important to me to spend periods of time in private religious thought and reflection" (Intrapersonal) and "I enjoy working in the activities of my religious organization" (Interpersonal). Participants rated each item on a 5-point Likert-Type scale ranging from 1 (not at all true of me) to 5 (totally true of me). Intrapersonal Religious Commitment was highly correlated with Interpersonal Religious Commitment (Worthington et al., 2003). The alpha coefficient for the RCI-10 was .95 (Allen \& Heppner, 2011) and the test-retest reliability over a 5-month period was .91 (Worthington et al., 2003).

Almost Perfect Scale-Revised (Slaney et al., 1996) is a 23item scale including three dimensions of perfectionism. The Standards subscale (seven items) assesses a person's expectations for individual performance (e.g., "I try to do my best at everything I do"). The Order subscale (four items) focuses on the individual's concern with organization and neatness (e.g., "I am an orderly person"). The Discrepancy subscale (12 items) measures an individual's perceived failure to live up to his or her high standards (e.g., "I am never satisfied with my accomplishments"). Participants use a 7-point Likert scale ranging from 1 (strongly disagree) to 7 (strongly agree) to respond to items. The internal consistency estimates for the subscales were in the high range: High Standards $=.85$, Order $=.86$, and Discrepancy $=.92$ (Slaney, Rice, Mobley, Trippi, \& Ashby, 2001).

Penn Inventory of Scrupulosity (Abramowitz et al., 2002) is a 19-item scale used to measure religious obsessive-compulsive symptoms. It includes two subscales: Fear of Sin and Fear of Punishment from God, which assess the level of fear around engaging in sinful activities (e.g., I am afraid of having sexual thoughts) and fears concerning punishment from God (e.g., I worry that God is upset with me), respectively. The composite score was used in this study. Items are rated on a Likert-type scale ranging from 0 (never) to 4 (constantly). Cronbach's alpha for the composite score was .93. (Abramowitz et al., 2002).

Depression Anxiety Stress Scale-21 (DASS-21; Lovibond \& Lovibond, 1995) includes three subscales: Depression, Anxiety, and Stress. The Depression (7 items; e.g., "I felt downhearted and blue") and Anxiety (7 items; e.g., "I felt I was close to panic") subscales were used in this study as psychological indicators. The DASS-21 assesses the emotional levels of depression, anxiety, and stress, and is rated on a Likert-type scale ranging from 0 (did not apply to me at all) to 3 (applied to me very much, or most of the time). Cronbach's alpha for the Depression and Anxiety subscale scores were .91 and .84, respectively (Lovibond \& Lovibond, 1995).

Rosenberg Self-Esteem Scale (RSES; Rosenberg, 1965) was used to assess self-esteem, as it has been frequently used among diverse populations (Phinney, 1996; Speight, 1996). The RSES consists of 10 Likert-type items ranging from 1 (strongly disagree) to 4 (strongly agree). Higher scores mean higher self-esteem. The RSES is designed to measure one's self-esteem (i.e., "On the whole, I am satisfied with myself" or "At times, I think I am no good at all") and has good internal reliability $(\alpha=.92$; Rosenberg, 1965).

Satisfaction With Life Scale (SWLS; Diener, Emmons, Larsen $\&$ Griffin, 1985) is a 5-item Likert-type instrument ranging from 1 (strongly disagree) to 7 (strongly agree) designed to assess global cognitive judgments of satisfaction with one's life (i.e., "I am satisfied with my life"). The internal consistency of the SWLS and alpha coefficients have repeatedly exceeded .80 in various studies (Pavot \& Diener, 1993). In Diener and colleagues' (1985) original study, they found an alpha coefficient of .87 .

\section{Results}

\section{Preliminary Analyses}

Missing data were screened and participants missing over a third of the items on a single measure were coded as missing for that particular variable. Prior to summing the subscale scores, the remaining random missing values at the item level (one person had 10 items, eight participants had three to six items, and 50 participants had one to two items missing) were replaced through the expectation-maximization (Dempster, Laird, \& Rubin, 1977) method, which uses an iterative method for finding maximum likelihood estimates. Univariate and multivariate outliers were examined following procedures described by Tabachnick and Fidell (2007). There were five cases that included univariate outliers that had absolute $\mathrm{Z}$ scores exceeding 3.3. We closely inspected the data of these cases and did not identify any invariant or problematic response patterns, thus, these cases were retained.

$t$-Tests and correlations were conducted to determine whether study variables varied as a function of participants' gender and age. The results indicated that men reported significantly higher self-esteem than women, $t=2.37, p<.05$ and that age significantly correlated with discrepancy, scrupulosity, self-esteem, and depression $(p<.05)$. Thus, gender and age were used as demographic covariates in the regression analyses. Descriptive statistics, intercorrelations, and Cronbach's alpha coefficients for the subscale scores are presented in Table 1.

\section{Moderation Analyses}

Following recommendations by Frazier, Tix, and Barron (2004), the predictors, moderators, and covariates were standardized to reduce multicollinearity. Three parallel hierarchical multiple regression analyses were conducted for satisfaction with life, anxiety, and depression. For each analysis, a two-way interaction term was created through the multiplication of Discrepancy $\times$ Scrupulosity. For each hierarchical regression, gender and age were entered as demographic covariates in Step 1. Two religious-related variables, intra religious commitment and inter religious commitment were entered in Step 2 as religious covariates. Discrepancy and scrupulosity were entered in Step 3 to examine their main effects above and beyond the covariates. Finally, the two-way interaction term was entered in Step 4.

Satisfaction with life. In Step 1, the demographic covariates did not account for significant amount of the variance in satisfaction with life (see Table 2). In Step 2, the two religious variables accounted for an additional $10 \%$ of the variance in Satisfaction with life, but neither of their beta coefficients was significant. In Step 3, discrepancy and scrupulosity accounted for an additional $21 \%$ of the variance in satisfaction with life. In Step 4, the two-way interaction did not account for additional variance in satisfaction with life.

Anxiety. In Steps 1 and 2, the demographic and religious covariates did not account for significant amount of the variance in 
Table 1

Intercorrelations Between Study Variables

\begin{tabular}{|c|c|c|c|c|c|c|c|c|c|c|c|c|}
\hline Variable & 1 & 2 & 3 & 4 & 5 & 6 & 7 & 8 & 9 & 10 & $M$ & $S D$ \\
\hline 1. Scrupulosity & .94 & & & & & & & & & & 24.87 & 14.10 \\
\hline 2. Intra commitment & .06 & .95 & & & & & & & & & 23.45 & 6.81 \\
\hline 3. Inter commitment & .05 & $.90^{* * *}$ & .89 & & & & & & & & 14.90 & 4.40 \\
\hline 4. Standards & -.08 & $.18^{*}$ & $.15^{*}$ & .83 & & & & & & & 44.28 & 4.66 \\
\hline 5. Order & $-.15^{*}$ & .10 & .09 & .54 & .80 & & & & & & 22.54 & 4.01 \\
\hline 6. Discrepancy & $.45^{* *}$ & $-.16^{*}$ & $-.22^{* *}$ & -.10 & -.05 & .93 & & & & & 39.69 & 16.34 \\
\hline 7. Self-esteem & $-.43^{* *}$ & $.19^{*}$ & $.20^{*}$ & $.26^{* * *}$ & .08 & $-.67^{\text {*** }}$ & .88 & & & & 32.87 & 5.59 \\
\hline 8. Satisfaction with life & $-.35^{* *}$ & $.32^{* * *}$ & $.31^{* *}$ & $.28^{* *}$ & $.15^{*}$ & $-.46^{* *}$ & $.59^{* *}$ & .89 & & & 26.33 & 6.91 \\
\hline 9. Anxiety & $.41^{* *}$ & -.03 & -.07 & $-.17^{*}$ & $-.13^{*}$ & $.50^{* *}$ & $-.51^{* *}$ & $-.39^{* *}$ & .77 & & 3.36 & 3.45 \\
\hline 10. Depression & $.42^{* *}$ & $-.17^{*}$ & $-.17^{*}$ & $-.31^{* * *}$ & $-.18^{*}$ & $.51^{* * *}$ & $-.65^{* * *}$ & $-.51^{* * *}$ & $.67^{* * *}$ & .87 & 4.18 & 4.19 \\
\hline
\end{tabular}

Note. Cronbach's alphas are displayed in bold.

${ }^{*} p<.05 .{ }^{* * *} p<.001$, two-tailed.

anxiety (see Table 2). In Step 3, discrepancy and scrupulosity accounted for an additional $29 \%$ of the variance in anxiety. In Step 4 , the two-way interaction did not account for additional variance in anxiety.
Depression. In Step 1, the demographic covariates accounted for $4 \%$ of the variance in depression and age was a significant inverse predictor (see Table 2). In Step 2, the two religious variables accounted for an additional $3 \%$ of the variance in de-

Table 2

A Hierarchical Multiple Regression Analysis Predicting Satisfaction With Life, Anxiety, and Depression From Discrepancy, Scrupulosity, and Their Interactions

\begin{tabular}{|c|c|c|c|c|c|c|}
\hline & $B$ & $S E \mathrm{~B}$ & $B$ & $R^{2}$ & $\Delta R^{2}$ & $\Delta F(d f \mathrm{~s})$ \\
\hline \multicolumn{7}{|l|}{ Satisfaction with life } \\
\hline Step 1 (demographic covariates) & & & & .00 & .00 & $.07(2,258)$ \\
\hline Gender & .13 & .87 & .01 & & & \\
\hline Age & .02 & .04 & .02 & & & \\
\hline Step 2 (religious covariates) & & & & .10 & .10 & $13.68(2,256)^{* * * *}$ \\
\hline Intra commitment & 1.71 & .93 & .25 & & & \\
\hline Inter commitment & .47 & .93 & .07 & & & \\
\hline Step 3 & & & & .31 & .21 & $38.56(2,254)^{* * * *}$ \\
\hline Discrepancy (Disc) & -1.77 & .43 & $-.26^{* * * *}$ & & & \\
\hline Scrupulosity (Scrp) & -2.12 & .42 & $-.31^{* * * *}$ & & & \\
\hline Step 4 & & & & .31 & .00 & $.70(1,253)$ \\
\hline Disc $\times$ Scrp & -.27 & .32 & -.05 & & & \\
\hline \multicolumn{7}{|l|}{ Anxiety } \\
\hline Step 1 (demographic covariates) & & & & .02 & .02 & $2.81(2,259)$ \\
\hline Gender & .75 & .43 & .11 & & & \\
\hline Age & -.03 & .02 & -.09 & & & \\
\hline Step 2 (religious covariates) & & & & .03 & .01 & $.59(2,257)$ \\
\hline Intra commitment & .25 & .48 & .07 & & & \\
\hline Inter commitment & -.43 & .48 & -.12 & & & \\
\hline Step 3 & & & & .32 & .29 & $55.53(2,255)^{* * * * *}$ \\
\hline Disc & .91 & .21 & $.27^{* * * *}$ & & & \\
\hline Scrp & 1.38 & .21 & $.40^{* * * * *}$ & & & \\
\hline Step 4 & & & & .33 & .01 & $3.53(1,254)$ \\
\hline Disc $\times$ Scrp & .30 & .16 & .11 & & & \\
\hline \multicolumn{7}{|l|}{ Depression } \\
\hline Step 1 (demographic covariates) & & & & .04 & .04 & $5.32(2,259)^{* *}$ \\
\hline Gender & .71 & .52 & .08 & & & \\
\hline Age & -.08 & .03 & $-.17^{* * *}$ & & & \\
\hline Step 2 (religious covariates) & & & & .07 & .03 & $4.21(2,257)^{*}$ \\
\hline Intra commitment & -.83 & .57 & -.20 & & & \\
\hline Inter commitment & .11 & .57 & .03 & & & \\
\hline Step 3 & & & & .33 & .26 & $43.64(2,255)^{* * * *}$ \\
\hline Disc & 1.06 & .25 & $.25^{* * * * *}$ & & & \\
\hline Scrp & 1.56 & .25 & $.37^{* * * * *}$ & & & \\
\hline Step 4 & & & & .33 & .00 & $.20(1,254)$ \\
\hline Disc $\times$ Scrp & .09 & .19 & .03 & & & \\
\hline
\end{tabular}

${ }^{*} p<.05 .{ }^{* * *} p<.01 .^{* * * *} p<.001$. 
pression, but neither of their beta coefficients was significant. In Step 3, discrepancy and scrupulosity accounted for an additional $26 \%$ of the variance in depression. In Step 4, the two-way interaction did not account for additional variance in depression.

\section{Mediation Analyses}

Mediation analyses were also conducted by examining direct and indirect effects between discrepancy and three outcome variables (i.e., satisfaction with life, anxiety, and depression). We conducted separate path analyses using Mplus 7 with direct paths from discrepancy to the three outcome variables as well as indirect paths via scrupulosity. Results indicated that scrupulosity partially mediated the relationship between discrepancy and the three outcome variables. For satisfaction with life, the standardized direct effect was $-.38(p<.001)$ and the standardized indirect effect was $-.08(p=.004)$. For anxiety, the standardized direct effect was $.40(p<.001)$ and the standardized indirect effect was .10 $(p<.001)$. For depression, the standardized direct effect was .41 $(p<.001)$ and the standardized indirect effect was $.11(p<.001)$.

\section{Classifying Perfectionists}

In this study, we used Rice and Ashby's (2007) cutoff scores to classify this sample into perfectionist groups-adaptive, maladaptive, and nonperfectionists. Adaptive perfectionists are characterized by having high standards without high discrepancy; maladaptive perfectionists are characterized by having both high standards and discrepancy; and nonperfectionists are characterized by not having high standards. The criteria for classification were that (a) participants with standards scores of 42 or above were classified as perfectionists and (b) among the perfectionists those with discrepancy scores of 42 or above were maladaptive perfectionists, whereas those with discrepancy scores below 42 were adaptive perfectionists. Based on this efficient classification method, 126 participants were classified as adaptive perfectionists, 81 as maladaptive perfectionists, and 60 as nonperfectionists. A chi-square test was conducted across gender and perfectionist type; results indicated that there were no significant difference, $\chi^{2}(2)=.22$, $p=.90$, in how the perfectionist groups were distributed between men and women.

\section{Analyses of Variances}

Analyses of variances were conducted to compare the perfectionists and nonperfectionists across all study variables (see Table 3). Maladaptive perfectionists had significantly higher scrupulosity scores than the other two groups. Adaptive perfectionists reported higher religious commitment, both intra and interpersonal, compared to nonperfectionists, but neither of these two groups significantly differed from maladaptive perfectionists. Adaptive perfectionists also reported lower levels of anxiety and depression as well as higher levels of self-esteem and satisfaction with life than the maladaptive and nonperfectionists, whereas the latter two groups did not differ on these four variables.

\section{Discussion}

This study may be the first to examine perfectionism and religious commitment with members from The Church of Jesus Christ of Latter-Day Saints. As more attention is focused on religiosity, specifically LDS people, in the United States, understanding their belief system and psychological well-being is important for those who are curious or may not be knowledgeable about this community. The elevated proportion of adaptive perfectionists may be associated with the standards LDS individuals aspire to maintain as well as a strong LDS moral code they strive to live by; and this group of perfectionists reported lower levels of depression and an elevated satisfaction with life, while viewing themselves as religiously committed.

Although the moderation analyses were not significant, scrupulosity (fear of sinful activity and fear of punishment from God) and discrepancy (maladaptive perfectionism) significantly predicted decreased satisfaction with life as well as, increased anxiety and depression, above and beyond religious commitment. These results could mean that when this LDS sample is faced with perceived failures around their high standards, they may feel overly fearful of making mistakes (committing sin)

Table 3

Means and Standard Deviations by Perfectionist Groups

\begin{tabular}{|c|c|c|c|c|c|c|c|c|}
\hline \multirow[b]{2}{*}{ Subscale } & \multicolumn{2}{|c|}{$\begin{array}{c}\text { Adaptive } \\
\text { perfectionists } \\
(n=126)\end{array}$} & \multicolumn{2}{|c|}{$\begin{array}{l}\text { Maladaptive } \\
\text { perfectionists } \\
\quad(n=81)\end{array}$} & \multicolumn{2}{|c|}{$\begin{array}{l}\text { Nonperfectionists } \\
\quad(n=60)\end{array}$} & \multirow[b]{2}{*}{$F$} & \multirow[b]{2}{*}{$\eta^{2}$} \\
\hline & $M$ & $S D$ & $M$ & $S D$ & $M$ & $S D$ & & \\
\hline Standards & $46.42^{\mathrm{a}}$ & 2.25 & $46.13^{\mathrm{a}}$ & 2.31 & $37.28^{\mathrm{b}}$ & 3.93 & 254.07 & .66 \\
\hline Order & $23.45^{\mathrm{a}}$ & 3.58 & $23.50^{\mathrm{a}}$ & 3.35 & $19.32^{\mathrm{b}}$ & 4.04 & 30.62 & .19 \\
\hline Discrepancy & $28.04^{\mathrm{a}}$ & 8.47 & $56.89^{\mathrm{b}}$ & 11.41 & $40.95^{\mathrm{c}}$ & 13.31 & 182.02 & .58 \\
\hline Scrupulosity & $20.82^{\mathrm{a}}$ & 11.65 & $31.00^{\mathrm{b}}$ & 16.64 & $25.21^{\mathrm{a}}$ & 12.16 & 14.03 & .10 \\
\hline Intra commitment & $24.93^{\mathrm{a}}$ & 6.08 & $23.01^{\mathrm{ab}}$ & 6.58 & $20.93^{\mathrm{b}}$ & 7.77 & 7.61 & .06 \\
\hline Inter commitment & $15.83^{\mathrm{a}}$ & 4.04 & $14.42^{\mathrm{ab}}$ & 4.29 & $13.59^{\mathrm{b}}$ & 4.87 & 6.23 & .05 \\
\hline Self-esteem & $35.75^{\mathrm{a}}$ & 4.16 & $29.65^{\mathrm{b}}$ & 5.42 & $31.14^{\mathrm{b}}$ & 5.42 & 43.64 & .25 \\
\hline Satisfaction with life & $29.40^{\mathrm{a}}$ & 4.99 & $23.30^{\mathrm{b}}$ & 7.45 & $23.93^{\mathrm{b}}$ & 6.98 & 28.71 & .18 \\
\hline Anxiety & $1.96^{\mathrm{a}}$ & 2.20 & $4.97^{\mathrm{b}}$ & 3.82 & $4.14^{\mathrm{b}}$ & 3.92 & 24.36 & .16 \\
\hline Depression & $2.30^{\mathrm{a}}$ & 2.48 & $5.81^{\mathrm{b}}$ & 4.27 & $5.93^{\mathrm{b}}$ & 5.21 & 29.13 & .18 \\
\hline
\end{tabular}

Note. All univariate $\mathrm{F}$ tests were significant at $p<.001$, except for intra commitment $(p=.001)$ and inter commitment $(p=.002)$. Values with different superscripts indicate significant within-row differences between the clusters using Tukey HSD post hoc comparisons, significant at $p<.05$. Values with two superscripts indicate that they are not significantly different from either of the two other groups. 
and worry about not pleasing God. Likewise, they may exhibit some sadness due to not feeling like they measure up to their standard of living. Thus, this tendency to not feel good enough and be fearful about it may ultimately lead to a lack of satisfaction with life. The mediation analyses also suggest that scrupulosity partially mediated the relationship between discrepancy and psychological functioning in this LDS sample. This finding could lead us to think that specific fears and worries around their perceived sinful activities and fear of God may be the direct result of elevated depression and anxiety as well as decreased satisfaction with life. These specific results could suggest that when one demonstrates high levels of maladaptive perfectionism (i.e., discrepancy) and scrupulosity, this could lead to a more fear-driven pattern of living and behaviors rather than faith-based approach to religiosity, and consequently a detrimental impact on one's well-being. However, whereas maladaptive perfectionism and scrupulosity may present some psychological difficulties, this sample also showed that having adaptive perfectionism (i.e., high standards) can promote positive functioning leading to greater religious commitment. This appears to be evident as the majority of the sample was classified as adaptive perfectionists, reporting elevated intra and interpersonal religious commitment to the LDS faith and decreased levels of anxiety and depression as well as elevated levels of self-esteem and satisfaction with life than the maladaptive and nonperfectionists.

Findings from this study provide several practical implications, as well as considerations when working with some highly religious LDS individuals in counseling. First, when working with these individuals around religious issues, generally speaking, it is critical to be aware that perfectionism is multidimensional in which there are positive and negative aspects. For those LDS members who may be struggling with the impact of perfectionism, it could possibly be helpful to differentiate between having high standards and the tendency to never feel satisfied with their performances. Coping with the seemingly internal critic rather than to lower the standards may be a better option in decreasing the impact of perfectionism because perfectionistic discrepancy is maladaptive, but high standards are not. Exploring one's perfectionistic discrepancy and how it is impacting his or her level of scrupulosity is also essential to understand their overall well-being. A possible strategy could be to help LDS individuals understand that their view of their faith could be distorted due to the perfectionistic discrepancy of never feeling like they are good enough, and not due to the high standards the LDS Church espouses. Thus, assisting them to inherently possess a more accurate perspective of God and their faith could allay the effects of perfectionistic discrepancy and scrupulosity. It is also worth noting the adaptive nature of having high standards in general and in the context of their faith. In other words, the goal may be to strive to reflect the image of God through daily behaviors and living (maintaining high standards), and at the same time know that one is still susceptible to sinful activities and to be able to reach healing from these feelings of guilt, fear, and inadequacy through forgiveness from God (lowering discrepancy). In addition, the well-established empirically based knowledge (Abdel-Khalek, 2011; Allen \& Heppner, 2011; Jackson \& Bergeman, 2011; Yeh, Arora, \& Wu, 2006; Yeh, Inman, Kim, \& Okubo, 2006) appears to support that being religiously committed can possibly be associated with heightened psychological health. This body of knowledge could also assist those who are highly religious to gain a desire to seek satisfaction with life. Thus, it may not necessarily be the commitment that leads to distress, but rather the focus on one's imperfection.

These results could have a lasting impact by generating clarity for LDS individuals who may be confused about their feelings of inadequacy, perceived imperfections, and the psychological and emotional consequences that follow. The administrative and organizational aspect of the LDS Church and those who are charged with leadership positions could examine and consider these results as potentially helpful to their congregations in understanding and helping LDS members who struggle with maladaptive perfectionism and scrupulosity. Additional sensitivity by clergypersons toward these members could open a doorway for communication and connection to happen between them and their distressed church members. The provision of psycho-educational information and pastoral counseling interventions about adaptive and maladaptive perfectionists that highlights the multidimensional nature of this construct and how it relates to mental health and religious factors could also help more accurately and appropriately redefine their psychological experiences.

Regarding limitations to this study, one worth mentioning is the age range of adults. The fact that the age mean was in the mid 20's does not allow researchers to infer generalizability across other age groups of LDS members. Factors in this age group such as life stage development and identity formulation could have influenced or overinflated the results in a direction toward perfectionism and scrupulosity that would otherwise not be found in other older age groups. For example, typically LDS members in this age group are encouraged to get married (and begin having children), achieve excellence in education, and plan for a successful and lucrative career. Thus, this added pressure could lead them to respond more favorably to endorsing elevated scores on being "perfect" and perhaps fearful of not succeeding in this phase of life. Future studies may include samples of different age groups as well as other regions of the United States and internationally, as ideas, beliefs, or perceptions of religious commitment, and specific fears around sin and punishment from God can be different among other faithful LDS individuals. In addition, future studies may also extend the literature by studying religious commitment, scrupulosity, and perfectionism with other religious groups in the United States as well as other countries. It would also be important to examine possible differences between people of mainstream and minority religious faiths as well as those with different types of doctrines (e.g., strict vs. lenient, conservative vs. liberal).

Another limitation is that this study was cross-sectional; thus, a causal relationship cannot be determined. Future studies may incorporate an experimental design to better understand the causal effects as well as further this line of research by using qualitative methods to better explore the underlying mechanism between maladaptive perfectionism and religiosity. This study was also based on self-report, which introduces the possibility of presenting oneself in a favorable manner regarding religiosity and psychological symptoms. Future studies may want to consider controlling for social desirability. Finally, because of the volunteer nature the recruitment process, those that participated might have possibly been more altruistic, compliant, and committed to their faith. Although these are limitations, the 
results still indicate a significant phenomenon related to how LDS members in this specific region religiously live in the world.

There remains a significant lack of research regarding people of LDS and other religious faiths. This study should stimulate interest of other educators, scholars, and researchers to advance this pioneering field of research forward. The results have assisted the understanding and knowledge base of LDS living, their drive for perfection, their worries about not living up to their expectations, and their overall well-being. In general, it offers a broader and clearer conception of members of the LDS Church who perhaps are having similar psychological experiences in the mainstream American culture. One of the main objectives of this study was to answer many questions that scientists and practitioners may have about this population in order to better serve them, but more importantly, the study should foster more understanding of the psychological well-being of some LDS individuals. Findings from this study may also have implications for individuals from other religious groups in the United States as well as other countries, which could be a next step in advancing the knowledge base. In sum, there are still many unanswered questions and much research yet to do for LDS and other religious populations.

\section{References}

Abdel-Khalek, A. M. (2011). Religiosity, subjective well-being, selfesteem, and anxiety among Kuwaiti Muslim. Mental Health, Religion \& Culture, 14, 129-140.

Abramowitz, J., Huppert, J., Cohen, A., Tolin, D., \& Cahill, S. (2002). Religious obsessions and compulsions in a non-clinical sample: The Penn Inventory of Scrupulosity (PIOS). Behaviour Research and Therapy, 40, 825-838.

Allen, G. E. K., \& Heppner, P. P. (2011). Religiostiy, coping, and psychological well-being among Latter-Day Saint Polynesians in the U.S. Asian American Journal of Psychology, 2, 1, 13-24.

Allport, G. W., \& Ross, M. (1967). Personal religious orientation and prejudice. Journal of Personality and Social Psychology, 5, 432-443.

Barrett, I. J. (1973). Joseph Smith and the restoration: A history of the church to 1846. Provo, UT: Brigham Young University Press.

Bergin, A. E. (1991). Values and religious issues in psychotherapy and mental health. American Psychologist, 46, 394-403.

Cervantes, J. M., \& Parham, T. A. (2005). Toward a meaningful spirituality for people of color: Lessons for the counseling practitioner. Cultural Diversity \& Ethnic Minority Psychology, 11, 69-81.

Craddock, A. E., Church, W., Harrison, F., \& Sands, A. (2010). Family of origin qualities as predictors of religious dysfunctional perfectionism. Journal of Psychology and Theology, 38, 205-214.

Crosby, J. M., Bates, S. C., \& Twohig, M. P. (2011). Examination of the relationship between perfectionism and religiosity as mediated by psychological inflexibility. Current Psychology: A Journal for Diverse Perspectives on Diverse Psychological Issues, 30, 117-129. doi: 10.1007/s12144-011-9104-3

Dempster, A. P., Laird, N. M., \& Rubin, D. B. (1977). Maximum likelihood from incomplete data via the EM algorithm. Journal of the Royal Statistical Society, Series B (Methodological), 1-38.

Diener, E., Emmons, R. A., Larsen, R. J., \& Griffin, S. (1985). The Satisfaction With Life Scale. Journal of Personality Assessment, 49, 71-75.

Foa, E. B., Kozak, M. J., Goodman, W. K., Hollander, E., Jenike, M. A., \& Rasmussen, S. A. (1995). DSM-IV field trial: Obsessive-compulsive disorder. American Journal of Psychiatry, 152, 90-96.
Frazier, P. A., Tix, A. P., \& Barron, K. E. (2004). "Testing moderator and mediator effects in counseling psychology research": Correction to Frazier et al. (2004). [Erratum/Correction]. Journal of Counseling Psychology, 51, 157.

Grzegorek, J. L., Slaney, R. B., Franze, S., \& Rice, K. G. (2004). Selfcriticism, dependency, self-esteem, and grade point average satisfaction among clusters of perfectionists and nonperfectionists. Journal of Counseling Psychology, 51, 192-200.

Jackson, B., \& Bergeman, C. S. (2011). How does religiosity enhance well-being? The role of perceived control. Psychology of religion and spirituality, 3, 149-161.

Lovibond, P., \& Lovibond, S. (1995). The structure of negative emotional states: Comparison of the Depression Anxiety Stress Scales (DASS) with the Beck Depression and Anxiety Inventories. Behaviour Research and Therapy, 33, 335-343.

Nelson, E. A., Abramowitz, J. S., Whiteside, S. P., \& Deacon, B. J. (2006). Scrupulosity in patients with obsessive-compulsive disorder: Relationship to clinical and cognitive phenomena. Journal of Anxiety Disorders, 20, 1071-1086.

Parham, T. A. (2002). Counseling persons of African descent. Thousand Oaks, CA: Sage.

Pavot, W., \& Diener, E. (1993). Review of the Satisfaction with Life Scale. Psychological Assessment, 5, 164-172.

Phinney, J. S. (1996). When we talk about American ethnic groups, what do we mean? American Psychologist, 51, 918-927.

Rice, K. G., \& Ashby, J. S. (2007). An efficient method for classifying perfectionists. Journal of Counseling Psychology, 54, 72-85. doi 10.1037/0022-0167.54.1.72

Rice, K. G., \& Slaney, R. B. (2002). Cluster of perfectionists: Two studies of emotional adjustment and academic achievement. Measurement and Evaluation in Counseling and Development, 35, 35-48.

Richards, P. S., \& Bergin, A. E. (1997). A spiritual strategy for counseling and psychotherapy. Washington, DC: American Psychological Association.

Richards, P., Owen, L., \& Stein, S. (1993). A religiously oriented group counseling intervention for self-defeating perfectionism: A pilot study. Counseling and Values, 37, 96-104. doi:10.1002/j.2161-007X.1993 tb00801.x

Rosenberg, M. (1965). Society and the adolescent self-image. Princeton, NJ: Princeton University Press.

Shafran, R., \& Mansell, W. (2001). Perfectionism and psychopathology: A review of research and treatment. Clinical Psychology Review, 21 879-906.

Slaney, R. B., Mobley, M., Trippi, J., Ashby, J. S., \& Johnson, D. G. (1996). The Almost Perfect Scale-Revised. Unpublished manuscript, The Pennsylvania State University, University Park.

Slaney, R. B., Rice, K. G., Mobley, M., Trippi, J., \& Ashby, J. S. (2001). The revised Almost Perfect Scale. Measurement and Evaluation in Counseling and Development, 34, 130-145.

Speight, S. L. (1996). Racial self-designation, racial identity, and selfesteem revisited. Journal of Black Psychology, 22, 37-52.

Stoeber, J., \& Otto, K. (2006). Positive conceptions of perfectionism: Approaches, evidence, challenges. Personality and Social Psychology Review, 10, 295-319.

Summerfeldt, L., Antony, M., Downie, F., Richter, M., \& Swinson, R. (1998). Prevalence of particular obsessions and compulsions in a clinic sample. Unpublished manuscript.

Tabachnick, B. G., \& Fidell, L. S. (2007). Using multivariate statistics (5th ed.). Boston, MA: Pearson.

Walsh, F. (1999). Religion and spirituality: Well-springs for healing and resilience. In F. Walsh (Ed.), Spiritual resources in family therapy (pp. 3-27). New York, NY: Guilford Press.

Wang, K. T. (2010). The Family Almost Perfect Scale: Development, psychometric properties, and comparing Asian and European Ameri- 
cans. Asian American Journal of Psychology, 1, 186-199. doi:10.1037/ a0020732

Worthington, E. L., Wade, N. G., Hight, T. L., Berry, J. W., Schmitt, M. M., Ripley, J. S., McCullough, M. E., Berry, J. T., Bursley, K. H., \& O'Connor, L. (2003). The religious commitment inventory-10: Development, refinement, and validation of a brief scale for research and counseling. Journal of Counseling Psychology, 50(1), 84-96.

Yeh, C. J., Arora, A. K., \& Wu, K. A. (2006). A new theoretical model of collectivistic coping. In P. T. P. Wong \& L. C. J. Wong (Eds.), Handbook of Multicultural Perspectives on Stress and Coping (pp. 56-60). New York, NY: Springer Science Business Media.
Yeh, C. J., Inman, A. C., Kim, A. B., \& Okubo, Y. (2006). Asian American families' collectivistic coping strategies in response to 9/11. Cultural Diversity \& Ethnic Minority Psychology, 12, 134-148.

Received October 29, 2012 Revision received September 9, 2013 Accepted October 14, 2013 